\title{
Advances in balloon endoscopes
}

\author{
Akihiro Araki $\cdot$ Kiichiro Tsuchiya $\cdot$ \\ Mamoru Watanabe
}

Received: 19 March 2014/ Accepted: 25 March 2014/Published online: 23 April 2014

(C) Springer Japan 2014

\begin{abstract}
In September 2003, a double-balloon endoscope (DBE) composed of balloons attached to a scope and an overtube was released in Japan prior to becoming available in other parts of the world. The DBE was developed by Dr. Yamamoto (1), and 5 different types of scopes with different uses have already been marketed. In April 2007, a single-balloon small intestinal endoscope was released with a balloon attached only to the overtube as a subsequent model. This article presents a detailed account of the development of these scopes up to the present time.
\end{abstract}

Keywords Double-balloon endoscopy $\cdot$ Single-operator method - Treatment - Double overtube - Continuous infusion · Single-balloon endoscopy · DBERCP · DBECS · Dilatation

\section{Introduction}

In September 2003, a double-balloon endoscope (DBE) composed of balloons attached to a scope and an overtube was released in Japan prior to becoming available in other parts of the world. The DBE was developed by Dr. Yamamoto [1], and 5 different types of scopes with different uses have already been marketed. We present a detailed account of the development of these scopes up to the present time.

A. Araki $(\bowtie) \cdot$ K. Tsuchiya $\cdot$ M. Watanabe

Department of Gastroenterology and Hepatology, Graduate

School, Tokyo Medical and Dental University, 1-5-45 Yushima,

Bunkyo-ku, Tokyo 113-8510, Japan

e-mail: araki.gast@tmd.ac.jp

\section{Types of DBE and changes}

There are 2 DBE models-one with a working length of $2 \mathrm{~m}$ that is designed to reach deep into the small intestine and the other with a working length of $1.5 \mathrm{~m}$ that is designed in consideration of operability in the bile duct/ large intestine or for reaching treatment tools.

Endoscopes with a small forceps channel diameter of $2.2 \mathrm{~mm}$ and with a large forceps channel diameter of 2.8 have also been released, and an endoscope with a larger diameter of $3.2 \mathrm{~mm}$ has recently been released. The difference in the forceps channel diameter also reflects the difference in the outside diameter. Large endoscopes are used when treatment is performed or when image quality is given priority. Small endoscopes are used when deep insertion is attempted or when it is necessary to reduce the examination burden on a patient (Table 1; Fig. 1).

First DBE P5 for observation of the small intestine. This is a small long-type endoscope used for the small intestine, large intestine, stomach, and duodenum.

Second DBE T5 for treatment of the small intestine. This is a large long-type endoscope with good image quality used for the small intestine, large intestine, stomach, and duodenum.

Third DBE BI5 for the large intestine (bile duct). . This is a large short-type endoscope with good image quality used for the large intestine as stipulated by the Japanese National Health Insurance program.

Fourth DBE EI530B for the bile duct. This is a large short-type endoscope with especially good image quality used for the esophagus, stomach, duodenum, small intestine, and large intestine as stipulated by the Japanese National Health Insurance program. 
Table 1 DBE specification

\begin{tabular}{lllllll}
\hline Body & Model & EN-450P5 & EN-450T5 & EC-450BI5 & EI-530B & EN-580T \\
\hline Release date & 2003.11 & 2004.7 & 2005.11 & 2011.6 & 2013.12 \\
Field of view & 1,201 & 1,401 & 1,401 & 1,401 & 1,401 \\
Observation range (mm) & $5-100$ & $5-100$ & $3-100$ & $3-100$ & $2-100$ \\
Forceps channel diameter (mm) & 2.2 & 2.8 & 2.8 & 2.8 & 3.2 \\
Working length (mm) & 2,000 & 2,000 & 1,520 & 1,520 & 2,000 \\
Total length (mm) & 2,300 & 2,300 & 1,820 & 1,820 & 2,300 \\
Distal end diameter (mm) & 8.5 & 9.4 & 9.4 & 9.4 & 9.4 \\
Flexible portion diameter (mm) & 8.5 & 9.4 & 9.3 & 9.3 & 9.3 \\
\hline Overtube $\quad$ Compatible model & TS-12140 & TS-13140 & TS-13101 & TS-13101 & TS-13102 \\
\hline$\quad$ Outside diameter (mm) & 12.2 & 13.2 & 13.2 & 13.2 & 13.2 \\
$\quad$ Inside diameter (mm) & 10 & 10.8 & 10.8 & 10.8 & 10.8 \\
$\quad$ Total length (mm) & 1,450 & 1,450 & 1,050 & 1,050 & 1,450 \\
\hline
\end{tabular}

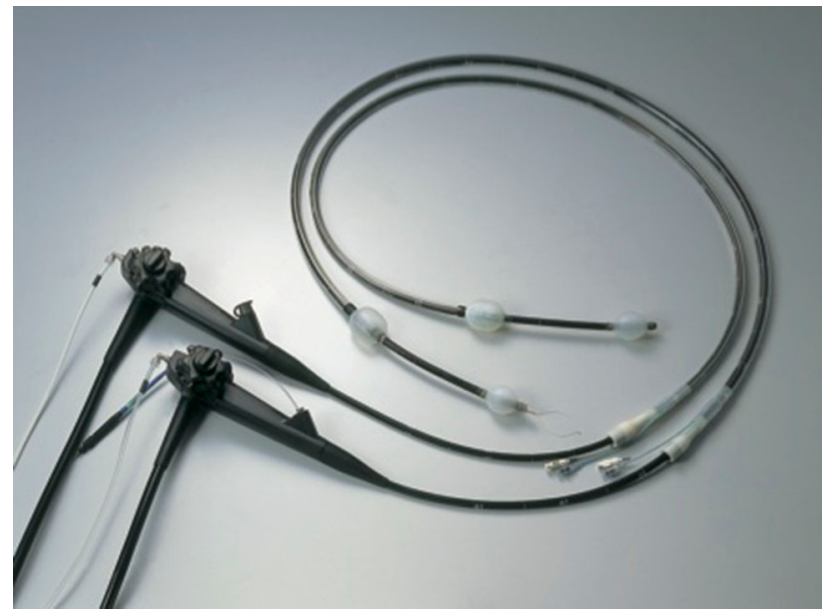

Fig. 1 P5 and T5

Fifth DBE EN580T for the small intestine, large intestine, stomach, and duodenum (successor model to T5). This is a large long-type endoscope with especially good image quality used for the esophagus, stomach, duodenum, small intestine, and large intestine as stipulated by the Japanese National Health Insurance program. A large forceps channel diameter $(3.2 \mathrm{~mm})$.

\section{Changes in overtubes}

Early first-generation overtube-the surface around the insertion port was clearly uneven, which facilitated hooking fingers on the overtube in the dual-operator method.

The second-generation overtube with a modified insertion port-because the uneven surface around the insertion

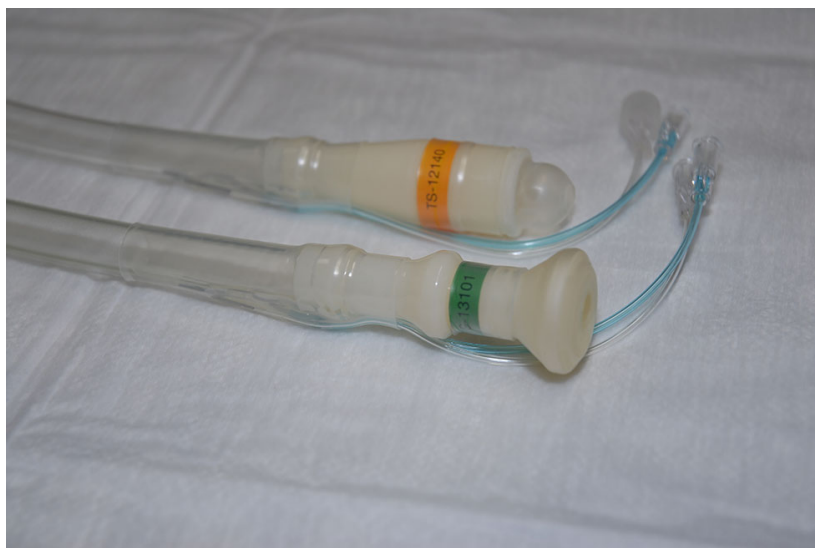

Fig. 2 Appearance of overtube

port was smoothed, insertion by the single-operator method became slightly more difficult.

The third-generation overtube with a modified insertion port - the form of the insertion port was modified to allow fingers to be hooked on the overtube even in the singleoperator method. This modification allowed an assistant to easily hook the fingers even in the dual-operator method, and either method became relatively easy to perform. Simultaneously, the form of the anti-leakage film was also changed from extended to plate-like (Fig. 2).

At present, 3 types of overtubes are available, and all 3 are compatible with the 5 types of DBE according to outside diameter and length.

Changes in the balloon at the tip

The balloon at the tip of the endoscope is called the 'tip balloon'. 
Because the inflated diameter of the tip balloon SB-1 was rather small at first, it was difficult to fix the balloon in the large intestine in some cases. This prompted the development of SB-2, a slightly larger balloon for the lower gastrointestinal tract. Subsequently, the use of this balloon became standard and production of the earlier balloon with the small diameter (SB-1) was stopped.

Changes in the hood

Although only black hoods used for observation were available at first, transparent hoods for treatment have also been released.

Hoods manufactured by other companies may also be usable. At our hospital, the adhesive part of band-aids is sometimes used for attaching the hood. In terms of waterresistant properties and adhesiveness, band-aids are often found to be more durable than other methods.

\section{Changes in balloon controllers}

In the early PB-10 model, the end of the tube was exposed to the full-size panel. With the successor model designated PB-20, handling of the tube became simpler, and the controller was equipped with an indicator showing balloon status. Furthermore, balloons could be displayed on an observation monitor.

\section{Changes in light sources}

When DBEs became commercially available, the light source system was the 4400 Sapientia Series.

Later, light sources improved and the 4450 Advancia HD Series was used. DBE becoming compatible with the LASEREO Series, which uses a laser light source, is eagerly anticipated. Ten patterns from the Fujinon intelligent chromoendoscopy (FICE) system are available for installation and can be used with any of the current types of endoscopes.

\section{Insertion methods}

\section{Dual-operator method}

The standard method is the dual-operator method. The operator controls the endoscope, while the assistant operates an overtube and a balloon controller.

Single-operator method (with tools)

A method of double-balloon endoscopy to be performed by a single operator was investigated, and methods using

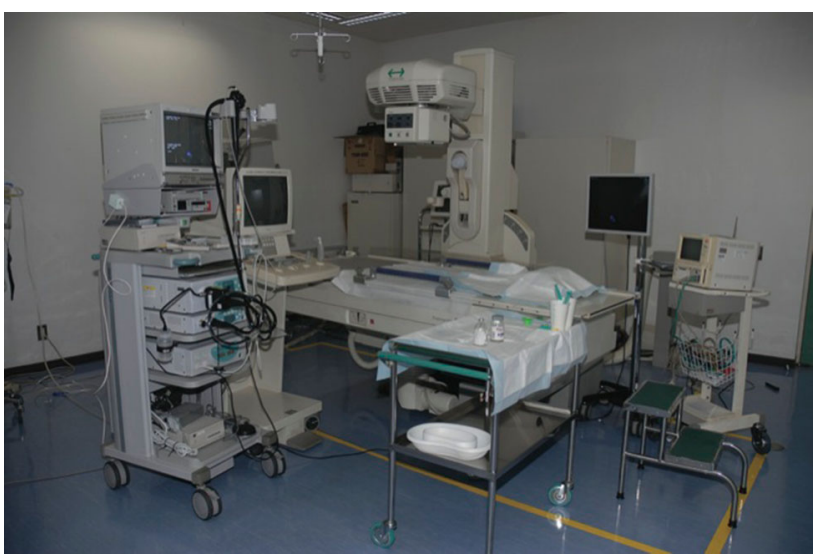

Fig. 3 Layout of equipment

specifically designed tools were developed at 3 institutions. These methods were reported at symposia of the 71st and 72nd Congresses of the Japan Gastroenterological Endoscopy Society [2] -(1) Yamamoto et al., Jichi Medical University: drip-stand type; (2) Abe et al., Osaka Police Hospital: Iron-Arm; and (3) Araki et al., Tokyo Medical and Dental University: small grasping device.

Single-operator method (without tool)

We previously reported a single-operator method that does not require the use of any type of tool. It was reported in Japan in 2006 and at Digestive Disease Week (DDW) in the United States in 2007. In Endoscopy, the official journal of the European Society of Gastrointestinal Endoscopy, this method was introduced as a key reference. It was suggested in the journal that only personnel who monitor the condition of a patient are needed because no assistant is required [3].

\section{$D B E$ insertion method: details for the single-operator method}

We originally introduced double-balloon endoscopy in September 2004. Although 2 operators are generally required for this test, we developed a single-operator method which allows one operator to perform the test; we reported this method in Japan before it was known throughout the rest of the world [4-6]. Based on our studies, there is no difference in the completion rate of total small intestinal observation or in total observation time between the single- and dual-operator methods. In the dualoperator method, the operator who controls the endoscope cannot obtain delicate sensation at the tip of the endoscope. However, we consider the single-operator method to be better in terms of operability because the sole operator obtains all the information. We recommend 


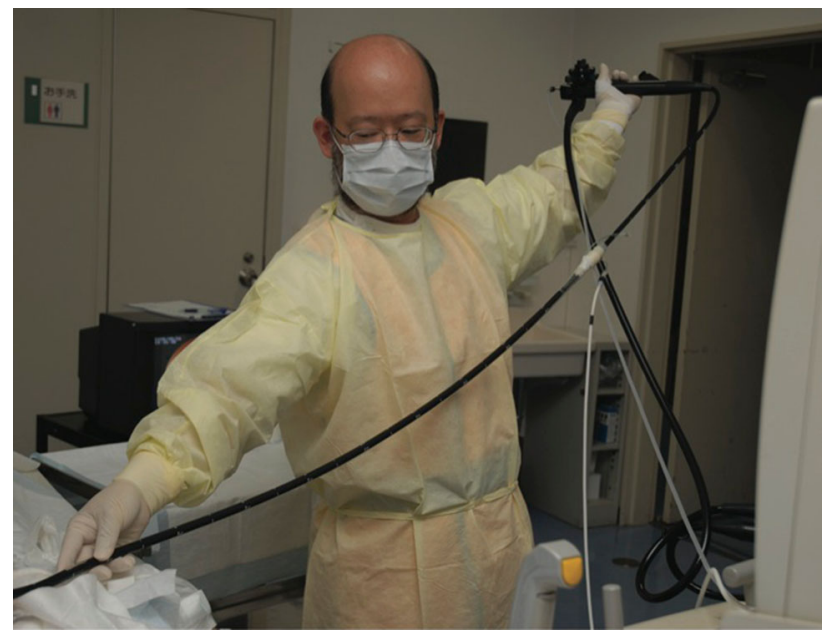

Fig. 4 Keep and slide technique

implementation of the single-operator method from the time of DBE introduction. Even if the dual-operator method has already been introduced, the transition to the single-operator method can be carried out by training whereby the single-operator method is first performed and then converted to the dual-operator method when the endoscopic procedure cannot be continued using the single-operator method.

Because we have also carried out conversion of colonoscopy from the dual-operator method to the single-operator method, we recommend introducing double-balloon endoscopy by the single-operator method from the beginning.

For preparation, the layout of an endoscopy room should be changed to facilitate performance of the procedure. For example, placement of a stand for an endoscope is necessary (Fig. 3).

\section{Actual insertion method}

We were able to successfully carry out a solo performance of double-balloon endoscopy by using the following techniques. The single-operator method is composed of the following 5 techniques ( 2 main techniques and 3 subtechniques).

The main techniques are (1) grip and pinch technique; and (2) keep and slide technique.

The sub-techniques are (3) abdominal support technique, (4) hooking technique; and (5) pull back and advance technique.

The single-operator method that we invented is performed according to the following procedure:

(1) The operator inserts an endoscope. (2) The operator inflates and fixes the tip balloon. (3) The operator slides an overtube to the tip of the endoscope. The operator holds the

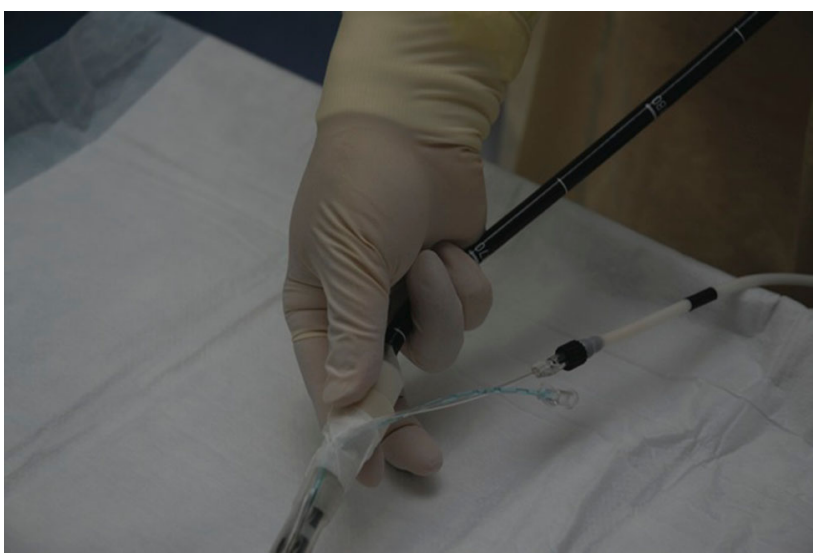

Fig. 5 Grip and pinch technique

endoscope control unit with the left hand in the same manner as in the ordinary endoscopic operation. Simultaneously, the overtube is held and inserted by the right hand (keep and slide technique) (Fig. 4). (4) The operator inflates and fixes the balloon at the tip of the overtube (the 'overtube balloon'). (5) The operator holds and pulls back the overtube and the endoscope with the right hand. (6) The operator deflates the tip balloon and inserts the endoscope into the overtube held by the operator. While holding the endoscope control unit with the left hand in the same manner as in the ordinary endoscopic operation, the operator manipulates the dial. Simultaneously, the endoscope is gripped by the fourth finger, fifth finger, and palm of the right hand and the overtube is then pinched with the first and second fingers of the right hand. While the overtube is held, the operator inserts and pulls back the endoscope by flexing and extending the first finger, second finger, and palm (grip and pinch technique) (Fig. 5).

In the event of no or inadequate force being transmitted or of strong resistance from the overtube, the operator should slightly bend the endoscope shaft with the right hand at the outside of the overtube while performing the grip and pinch technique. Then, the operator should push the curved section with his/her abdomen to prevent the endoscope from sliding backwards through the overtube (abdominal support technique).

Alternatively, the operator should hold the overtube with the fourth and fifth fingers of the left hand and insert the endoscope with the right hand toward the overtube (hooking technique).

When the tip of the endoscope is not adequately advanced, it may also be effective to advance the endoscope with tension applied to the intestine by inflating the overtube balloon and pulling it back slightly. The operator should perform the grip and pinch technique while slightly pulling back the overtube fixed to the intestine (pull back and advance technique). 


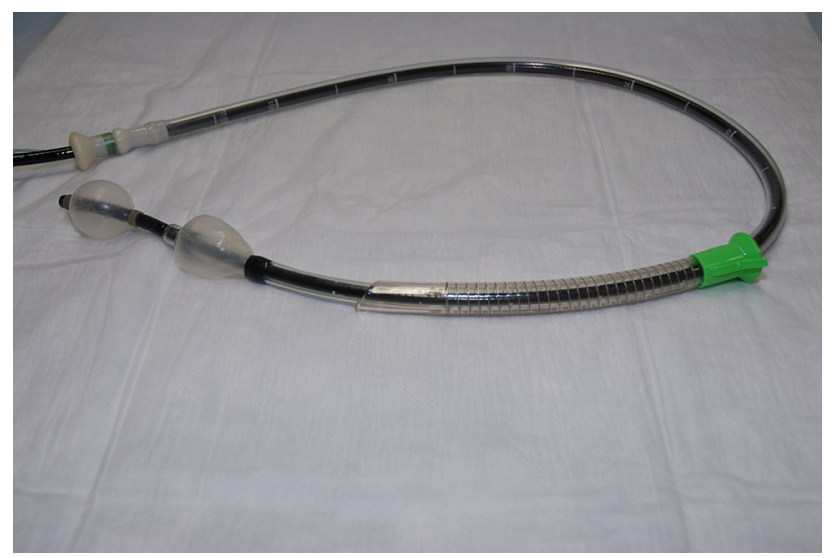

Fig. 6 Double overtube technique

\section{Innovation for smoother performance of double-balloon endoscopy}

Double overtube method

When an endoscope is inserted from the mouth (insertion via the upper gastrointestinal tract), we perform the double overtube method (second overtube method), our own innovation. In this method, an overtube is covered with a second overtube (flexible overtube; Sumitomo Bakelite Co., Ltd), in order to prevent aspiration and to reduce discomfort due to the back-and-forth passage of an endoscope through the subject's throat (Fig. 6). Insertion of the first flexible overtube requires meticulous technique and high skill. The esophageal mucosa is drawn between the flexible overtube and a double-balloon overtube employing a rather cumbersome operation, which is associated with a risk of perforation. In an interview survey conducted on 10 subjects, all 10 reported that discomfort was lower during use of the double overtube method.

\section{Continuous drip infusion method}

The overtube used for DBE is lined with a hydrophilic coating. If the lumen of the overtube is wet, the endoscope can be inserted very smoothly. Thus, it is necessary to frequently inject water from the water injection port of the overtube with a syringe. Because this process is timeconsuming and also cumbersome, the lumen is kept irrigated by continuous infusion of physiological saline from the water injection port of the overtube. This is called the continuous overtube injection technique. It reduced the mean duration from insertion to observation from $100 \mathrm{~min}$ in the single-operator method without injection to $83.8 \mathrm{~min}$ in the method with injection. Although tap water can be injected into the overtube instead of physiological saline, we prefer physiological saline for risk management in the event of incorrect connection to the drip infusion line.

\section{Treatment}

Endoscopic ultrasound (EUS)

With models with a forceps channel diameter of $2.8 \mathrm{~mm}$, such as therapeutic DBE, an EUS miniature probe can be used. The previous model of the EUS system manufactured by Fujifilm can also be used if the protective cover at the base of the probe is removed (the operator is held personally responsible for making sure this is performed). Meanwhile, the probe of the new model SP702, which is designed in consideration of possible use with the DBE, can be used without any particular modifications. The tip balloon is inflated at the area proximal to a lesion, and water is delivered from the forceps channel port or by pressing the water-delivery button to immerse the lesion. A miniature probe is then inserted from the forceps channel port to perform a test.

\section{Argon plasma coagulation (APC)}

APC can be performed with a reusable probe for the large intestine (reusable flexible APC probe $3000 \mathrm{~A}$, direct irradiation, with a diameter of $2.3 \mathrm{~mm}$ and length of $3 \mathrm{~m}$ ) if the therapeutic DBE is equipped with a forceps channel port with a diameter of $2.8 \mathrm{~mm}$. With the observation DBE model with a forceps channel diameter of $2.2 \mathrm{~mm}$, a small, long-type disposable probe that is available on the market can be used (disposable flexible APC probe $3000 \mathrm{~A}$, direct irradiation, with a diameter of $1.5 \mathrm{~mm}$ and length of $3 \mathrm{~m}$ ). At institutions where observation DBE model P-5 is used, this APC probe should always be kept prepared for prompt use because treatment can become difficult in the event of bleeding, for example, at the time of biopsy or local injection. Recently, manufacturers have stopped selling reusable probes, and all currently available probes are disposable.

\section{Clip}

Olympus: Rotating Clip Device HX-110UR. Sheath length: 2,300 mm; applicable channel diameter: $2.8 \mathrm{~mm}$ or more.

Boston Scientific: Resolution ${ }^{\mathrm{TM}}$ Clip Device. Sheath length: $2350 \mathrm{~mm}$; applicable channel diameter: $2.8 \mathrm{~mm}$.

Both devices described above can be used with models with a forceps channel diameter of $2.8 \mathrm{~mm}$. When the devices are inserted deep into the gastrointestinal tract through a $2-\mathrm{m}$ endoscope, they can be manipulated more 
easily using an endoscope with a forceps channel diameter of $3.2 \mathrm{~mm}$.

\section{Retrieval}

A retained capsule endoscope must be surgically retrieved if no DBE is available. Tanaka et al. [7] reported on retrieval of a capsule endoscope by DBE. For retrieval of endoscopically resected polyps and foreign bodies, retrieval baskets manufactured by US Endoscopy are commercially available. They can be used with a DBE with a forceps channel diameter of $2.8 \mathrm{~mm}$. The total length of the control unit is $230 \mathrm{~mm}$, and the maximum width of the basket is $30 \mathrm{~mm}$.

Super-selective double-contrast small bowel series with a tip balloon

In order to confirm a lesion, a small bowel series using contrast medium may need to be performed after insertion deep into a portion of the gastrointestinal tract. In such an event, DBE allows super-selective contrast series to be performed by occluding the intestine with the tip balloon. If the target site fails to be reached, the lesion can still be confirmed by this contrast series.

\section{Dilatation of intestinal strictures}

Due to the advent of DBE, it has become possible to dilate strictures caused by nonsteroidal anti-inflammatory drugs (NSAIDs)-induced ulcers or Crohn's disease with a balloon, even when deep in the small intestine. Membranelike strictures caused by NSAIDs are a good indication for balloon dilatation. In the case of Crohn's disease, balloon dilatation is well indicated for a stricture with a major axis of $\leq 2 \mathrm{~cm}$ that is not accompanied by ulceration.

A literature search using 'DBE' and 'dilatation' as key words yielded 10 articles [8-17].

With a DBE, stenotic lesions can be dilated in both the large and small intestines. Fukumoto et al. detected a stricture in 179 of 1,035 patients undergoing double-balloon endoscopy at 7 Japanese institutions and attempted dilatation of these lesions. The long-term patency success rates were $73.9 \%$ in patients with Crohn's disease and $75 \%$ in those with NSAIDs-induced ulcers [8].

Ohmiya et al. performed dilatation of 47 lesions in 22 patients using a DBE. They used 8- and 20-mm balloons manufactured by Boston Scientific (CRE Wireguided Balloon Dilators, for the upper and the lower gastrointestinal tract). After the lesions had been dilated with the smaller balloon, they were dilated again with the larger balloon. The success rate was reported to be $96 \%$ [9].
A literature search using 'single-balloon endoscope (SBE) dilatation' as the key word yielded 4 articles [1820]. None reported any data on dilatation of the gastrointestinal tract using SBE.

Double-balloon endoscopic retrograde cholangiopancreatography (DBERCP), double-balloon endoscopic sphincterotomy (DBEST), double-balloon endoscopic papillary balloon dilatation (DPEPBD)

T-5 was used for approaching the bile duct before specialized devices for the bile duct became commercially available. In the early days, because no device with a working length of $>2 \mathrm{~m}$ was available, the approach using T-5 was performed in the following manner-the orifice of the bile duct was approached with the T-5, and an overtube was placed. The proximal section of the overtube outside of the body was then cut by approximately $50 \mathrm{~cm}$ without cutting the tube for balloons. The subsequent procedures were performed under fluoroscopic guidance or by replacing the T-5 with a smaller endoscope or a conventional upper gastrointestinal endoscope. Later, the short BI5 was released, and all conventional devices have been usable since then. At institutions not equipped with a BI-5, a combination of T-5 and the overtube for BI- 5 followed by replacement of $\mathrm{T}-5$ with a conventional endoscope allows the procedure to be performed without cutting the overtube. Due to restrictions mandated by the National Health Insurance program in Japan, it will be necessary to use the EI530B for approaching the bile duct in the future. Since 2004, there have been reports by Sunada et al., Sugano et al., Endo et al., and Shimatani et al. in Japanese [21-24].

For dilatation of the bile duct, a balloon for the bile duct is used (CRE WG, Boston Scientific). After dilatation, a crusher is used, and the balloon is retrieved by a retriever balloon. A Xemex Crusher Catheter (Zeon Medical) which can be used with an endoscope with a forceps channel diameter of $2.8 \mathrm{~mm}$ is used as the crusher. Recently, at our department, we have also been using balloons 12-15 mm in diameter (CRE Biliary Dilation Balloon, 10-20 mm, available in 4 types, Boston Scientific) that are larger than those for the bile duct in some cases. Because lithotripsy is often unnecessary, the use of larger balloons allows endoscopic papillary large balloon dilatation (EPLBD) to be carried out smoothly. Moreover, in some patients with a preserved papilla, insertion is difficult because the papilla is vertically aligned. However, insertion can be achieved by using a sphincterotome, an endoscopic sphincterotomy (EST) knife (Autotome RX; Boston Scientific).

A literature search in PubMed using 'DBE endoscopic retrograde cholangiopancreatography (ERCP)' as the key word yielded 47 articles [25-63]. May et al. [25] published 
a report in 2007, and there is also a report on short DBEs published in 2010 [26] by Shimatani et al.

A literature search using 'SBE ERCP' as the key word yielded 14 articles [64-78]. Aktas and Mensink [64] published a report in 2008. There are also reports published by Dellon et al. [65], by Neumann et al. [66], and by Itoi et al. [67] in 2009.

\section{Double-balloon endoscopic colonoscope (DBECS)}

DBE is not only applied to the small intestinal region but also in cases where it is difficult to insert a colonoscope. A literature search in PubMed using 'DBE colonoscopy' as the key word yielded 53 articles [79-131]. Araki et al. [79] retrospectively examined 33 patients undergoing double-balloon endoscopy using the dual-operator method and 151 patients undergoing the procedure using the single-operator method at one institution between 2007 and 2009, reporting the rates of reaching the cecum to be $100 \%$ for both methods. In 2012, Hotta et al. [80] performed DBECS in 110 patients in whom insertion of a colonoscope was difficult, reporting that the rate of insertion to the cecum was $100 \%$ (multicenter/prospective study). Regarding studies on single-balloon endoscopy performed in patients in whom insertion of a colonoscope was difficult, a literature search using 'SBE colonoscopy' as the key word yielded 9 articles [132141]. In 2010, Teshima et al. [132] performed singleballoon endoscopic colonoscope (SBECS) in 22 patients in whom insertion was difficult, reporting that the rate of insertion to the cecum was $96 \%$.

\section{SBE}

In April 2007, Olympus released a single-balloon small intestinal endoscope with a balloon attached only to the overtube as a subsequent model. Its advantage is considered to be the ability to perform narrow-band imaging (NBI). Spraying with $0.3 \%$ crystal violet solution for marking allows preparation in the event of dislocation during insertion. At present, one model is available on the market, and its endoscope specifications are similar to those of the DBE model T5. Because there is no tip balloon, the insertion method for the SBE is different from that for the DBE. The SBE tip is bent and hooked on the intestine to be fixed. Future reports on assessment of NBI of the small intestine are awaited. There are also articles comparing insertability between the SBE and the DBE. May et al. [142] who removed the tip balloon from the DBE to use it as an SBE and compared it with the conventional $\mathrm{DBE}$, reported that the completion rates of total small intestinal observation were $66 \%$ for the DBE and
$22 \%$ for the SBE, showing a significant difference. Takano et al. [143], who compared completion rates of total small intestinal observation between commercially available DBEs and commercially available SBEs, reported that the rates were $57 \%$ for the DBE and $0 \%$ for the SBE, showing a significant difference.

\section{Conclusion}

We have described the changes in DBEs and SBEs, peripheral devices, and operating methods. Balloon endoscopy as a form of small intestinal endoscopy may contribute to elucidation of small intestinal lesions, as well as their causes and treatments. Moreover, because parts of the gastrointestinal tract that had been inaccessible to previous endoscopes have now become accessible, the DBE as an ultimate endoscope due to its range of applications may especially contribute to treating postoperative intestinal conditions and cases in which insertion of a colonoscope is difficult.

\section{Disclosures}

Conflict of Interest: Akihiro Araki and Kiichiro Tsuchiya declare that they have no conflict of interest. Mamoru Watanabe have served as consultants for and received speaker's fee and research grants from the following. AbbVie GK, Eisai Co., Ltd, Kyorin Pharmaceutical Co., Ltd, Mitsubishi Tanabe Pharma Co., Ltd, DAIICHI SANKYO Co., Ltd, Ono Pharmaceutical Co., Ltd, Gene Care Research Institute Co., Ltd, Astellas Pharma Inc., Asahi Kasei Kuraray Medical Co., Ltd, MSD K.K., Mitsubishi Tanabe Pharma Co., Ltd, Chugai Pharmaceutical Co., Ltd, Takeda Pharmaceutical Co., Ltd, Ajinomoto Pharma Co., Ltd, Otsuka Pharma Co., Ltd, Kyowa Hakko Kirin Co., Ltd, JIMRO Co., Ltd, Zeria Pharmaceutical Co., Ltd, UCB Japan Co., Ltd, Dainippon Sumitomo Pharma Co., Ltd, Toray Industries Inc., Bristol-Myers K.K.

Human/Animal Rights: All procedures followed were in accordance with the ethical standards of the responsible committee on human experimentation (institutional and national) and with the Helsinki Declaration of 1975, as revised in 2008(5).

Informed Consent: Informed consent was obtained from all patients for being included in the study.

\section{References}

1. Yamamoto H, Sekine Y, Sato Y, et al. Total enteroscopy with a nonsurgical steerable double-balloon method. Gastrointest Endosc. 2001;53(2):216-20.

2. Yamamoto H. Gastroenterol Endosc (0387-1207). 48(Suppl 2):Page2044 (2006.09) (in Japanese).

3. Mönkemüller K, Bellutti M, Malfertheiner P. Small-bowel endoscopy. Endoscopy. 2007;39(11):978-85. doi:10.1055/s2007-966927.

4. Araki A, Tsuchiya K, Okada E, et al. Single-operator method for double-balloon endoscopy: a pilot study. Endoscopy. 2008;40(11):936-8. 
5. Araki A, Tsuchiya K, Okada E, et al. Single-operator doubleballoon endoscopy (DBE) is as effective as dual-operator DBE. J Gastroenterol Hepatol. 2009;24(5):770-5.

6. Araki A, Suzuki S, Tsuchiya K, et al. Modified single-operator method for double-balloon endoscopy. Dig Endosc. 2012;24(6):470-4.

7. Tanaka S, Mitsui K, Shirakawa K, et al. Successful retrieval of video capsule endoscopy retained at ileal stenosis of Crohn's disease using double-balloon endoscopy. J Gastroenterol Hepatol. 2006;21(5):922-3.

8. Fukumoto A, Tanaka S, Yamamoto $\mathrm{H}$, et al. Diagnosis and treatment of small-bowel stricture by double balloon endoscopy. Gastrointest Endosc. 2007;66:S108-12.

9. Ohmiya N, Arakawa D, Nakamura M, et al. Small-bowel obstruction: diagnostic comparison between double-balloon endoscopy and fluoroscopic enteroclysis, and the outcome of enteroscopic treatment. Gastrointest Endosc. 2009;69:84-93.

10. Heine GD, Al-Toma A, Mulder CJ, Jacobs MA. Milestone in gastrointestinal endoscopy: double-balloon enteroscopy of the small bowel. Scand J Gastroenterol Suppl. 2006;243:32-8.

11. Hirai F, Beppu T, Sou S, et al. Endoscopic balloon dilatation using double-balloon endoscopy is a useful and safe treatment for small intestinal strictures in Crohn's disease. Dig Endosc. 2010;22:200-4.

12. Kida A, Matsuda K, Hirai S, et al. A pedunculated polyp-shaped small-bowel lymphangioma causing gastrointestinal bleeding and treated by double-balloon enteroscopy. World J Gastroenterol. 2012;18:4798-800.

13. Ono S, Maeda K, Baba K, et al. The efficacy of double-balloon enteroscopy for intrahepatic bile duct stones after Roux-en-Y hepaticojejunostomy for choledochal cysts. Pediatr Surg Int. 2013;29:1103-7.

14. Sanada Y, Mizuta K, Yano T, et al. Double-balloon enteroscopy for bilioenteric anastomotic stricture after pediatric living donor liver transplantation. Transpl Int. 2011;24:85-90.

15. Sunada K, Yamamoto H, Yano T, Sugano K. Advances in the diagnosis and treatment of small bowel lesions with Crohn's disease using double-balloon endoscopy. Ther Adv Gastroenterol. 2009;2:357-66.

16. Tamura H, Ogata K, Kondo A, et al. Double balloon endoscopy as a useful tool for the diagnosis and treatment of four cases of primary small intestinal lymphoma. Rinsho Ketsueki. 2007; 48:510-3.

17. Tharian B, Caddy G, Tham TC. Enteroscopy in small bowel Crohn's disease: a review. World J Gastrointest Endosc. 2013;5:476-86.

18. Calabrese E, La Seta F, Buccellato A, et al. Crohn's disease: a comparative prospective study of transabdominal ultrasonography, small intestine contrast ultrasonography, and small bowel enema. Inflamm Bowel Dis. 2005;11:139-45.

19. La Seta F, Buccellato A, Albanese M, et al. Radiology and adult celiac disease. Current indications of small bowel barium examinations. Radiol Med. 2004;108:515-21.

20. Ritvo R, Monroe P, Andriole VT. Transient bacteremia due to suction abortion: implications for SBE antibiotic prophylaxis. Yale J Biol Med. 1977;50:471-9.

21. Sunada K, Yamamoto H, Sugano K, et al. Usefulness of double balloon endoscopy with altered gastrointestinal anatomy. Gastroenterol Endosc (0387-1207). 46(Suppl 1):Page558 (2004.04) (in Japanese).

22. Sugano K, Yamamoto H, Kita H, et al. Double-balloon endoscopy. Theory and practice. Tokyo: Springer; 2005. p. 107.

23. Endo M, Inomata M, Terui $\mathrm{T}$, et al. Postoperative endoscope insertion into the intestinal tract: specifically after Roux-en-Y anastomosis. Endoscopia Digestiva (0915-3217). 19(11):1537-44 (2007.11) (in Japanese).
24. Shimatani M, Takaoka R, Okazaki K, et al. Usefulness of double balloon endoscopy with altered gastrointestinal anatomy. Gastroenterol Endosc (0387-1207). 49(Suppl 1):Page720 (2007.04) (in Japanese).

25. May A, Nachbar L, Pohl J, Ell C. Endoscopic interventions in the small bowel using double balloon enteroscopy: feasibility and limitations. Am J Gastroenterol. 2007;102:527-35.

26. Shimatani M, Matsushita M, Takaoka M, et al. Effective "short" double-balloon enteroscope for diagnostic and therapeutic ERCP in patients with altered gastrointestinal anatomy: a large case series. Endoscopy. 2009;41:849-54.

27. Aabakken L, Bretthauer M, Line PD. Double-balloon enteroscopy for endoscopic retrograde cholangiography in patients with a Roux-en-Y anastomosis. Endoscopy. 2007;39:1068-71.

28. Aktas H, Mensink PB. Therapeutic balloon-assisted enteroscopy. Dig Dis. 2008;26:309-13.

29. Cho S, Kamalaporn P, Kandel G, et al. 'Short' double-balloon enteroscope endoscopic retrograde cholangiopancreatography in patients with a surgically altered upper gastrointestinal tract. Can J Gastroenterol. 2011;25:615-9.

30. Chu YC, Yang CC, Yeh YH, et al. Double-balloon enteroscopy application in biliary tract disease-its therapeutic and diagnostic functions. Gastrointest Endosc. 2008;68:585-91.

31. Das A. Future perspective of double balloon endoscopy: newer indications. Gastrointest Endosc. 2007;66:S51-3.

32. Fähndrich M, Sandmann M, Heike M. A facilitated method for endoscopic interventions at the bile duct after Roux-en-Y reconstruction using double balloon enteroscopy. Z Gastroenterol. 2008;46:335-8.

33. Gerson LB, Tokar J, Chiorean M, et al. Complications associated with double balloon enteroscopy at nine US centers. Clin Gastroenterol Hepatol. 2009;7:1177-82, 1182.e1-3.

34. Ikeura T, Shimatani M, Takaoka M, et al. Intrahepatic cholangiocarcinoma diagnosed via endoscopic retrograde cholangiopancreatography with a short double-balloon enteroscope. World J Gastroenterol. 2013;19:4427-31.

35. Itaba S, Nakamura K, Aso A, et al. Prospective, randomized, double-blind, placebo-controlled trial of ulinastatin for prevention of hyperenzymemia after double balloon endoscopy via the antegrade approach. Dig Endosc. 2013;25:421-7.

36. Itoi T, Ishii K, Sofuni A, et al. Long- and short-type doubleballoon enteroscopy-assisted therapeutic ERCP for intact papilla in patients with a Roux-en-Y anastomosis. Surg Endosc. 2011;25:713-21.

37. Koornstra JJ. Double balloon enteroscopy for endoscopic retrograde cholangiopancreaticography after Roux-en-Y reconstruction: case series and review of the literature. Neth J Med. 2008;66:275-9.

38. Koshitani T, Matsuda S, Takai K, et al. Direct cholangioscopy combined with double-balloon enteroscope-assisted endoscopic retrograde cholangiopancreatography. World J Gastroenterol. 2012;18:3765-9.

39. Kuga R, Furuya CK, Hondo FY, et al. ERCP using doubleballoon enteroscopy in patients with Roux-en-Y anatomy. Dig Dis. 2008;26:330-5.

40. Kulaksiz H, Strnad P, Römpp A, et al. A novel method of forceps biopsy improves the diagnosis of proximal biliary malignancies. Dig Dis Sci. 2011;56(2):596-601.

41. Langers AM, De Vos tot Nederveen Cappel WH, Veenendaal RA, Bonsing BA, Hardwick JC, Vasen HF. Double balloon endoscopy for detection of small-bowel adenomas in familial adenomatous polyposis after pancreaticoduodenectomy according to Whipple. Endoscopy. 2008;40:773-4.

42. Lin $\mathrm{CH}$, Tang JH, Cheng CL, et al. Double balloon endoscopy increases the ERCP success rate in patients with a history of Billroth II gastrectomy. World J Gastroenterol. 2010;16:4594-8. 
43. Lo SK. Small bowel endoscopy: have we conquered the final frontier? Am J Gastroenterol. 2007;102:536-8.

44. Maaser C, Lenze F, Bokemeyer M, et al. Double balloon enteroscopy: a useful tool for diagnostic and therapeutic procedures in the pancreaticobiliary system. Am $\mathrm{J}$ Gastroenterol. 2008;103:894-900.

45. Maiss J, Diebel H, Naegel A, et al. A novel model for training in ERCP with double-balloon enteroscopy after abdominal surgery. Endoscopy. 2007;39:1072-5.

46. Mönkemüller K, Fry LC, Bellutti M, Neumann H, Malfertheiner P. ERCP with the double balloon enteroscope in patients with Roux-en-Y anastomosis. Surg Endosc. 2009;23:1961-7.

47. Moreels TG, Pelckmans PA. Comparison between double-balloon and single-balloon enteroscopy in therapeutic ERC after Roux-en-Y entero-enteric anastomosis. World J Gastrointest Endosc. 2010;2:314-7.

48. Okabe Y, Kuwaki K, Kawano H, et al. Direct cholangioscopy using a double-balloon enteroscope: choledochojejunostomy with intraductal biliary carcinoma. Dig Endosc. 2010;22:319-21.

49. Osoegawa T, Motomura Y, Akahoshi K, et al. Improved techniques for double-balloon-enteroscopy-assisted endoscopic retrograde cholangiopancreatography. World J Gastroenterol. 2012;18:6843-9.

50. Park JH, Ye BD, Byeon JS, et al. Approaching pancreatic duct through pancreaticojejunostomy site with double balloon enteroscope in patient with Roux-en-Y anatomy. Hepatogastroenterology. 2013;60:1753-8.

51. Parlak E, Ciçek B, Dişibeyaz S, et al. Endoscopic retrograde cholangiography by double balloon enteroscopy in patients with Roux-en-Y hepaticojejunostomy. Surg Endosc. 2010;24:466-70.

52. Patel MK, Horsley-Silva JL, Gómez V, et al. Double balloon enteroscopy procedure in patients with surgically altered bowel anatomy: analysis of a large prospectively collected database. J Laparoendosc Adv Surg Tech A. 2013;23:409-13.

53. Raithel M, Dormann H, Naegel A, et al. Double-balloonenteroscopy-based endoscopic retrograde cholangiopancreatography in post-surgical patients. World $\mathrm{J}$ Gastroenterol. 2011;17:2302-14.

54. Ryozawa S, Iwamoto S, Iwano H, et al. ERCP using doubleballoon endoscopes in patients with Roux-en-Y anastomosis. J Hepatobiliary Pancreat Surg. 2009;16:613-7.

55. Schilling D, Rosenbaum A, Schweizer S, Richter H, Rumstadt B. Sedation with propofol for interventional endoscopy by trained nurses in high-risk octogenarians: a prospective, randomized, controlled study. Endoscopy. 2009;41:295-8.

56. Shah RJ, Smolkin M, Yen R, et al. A multicenter, U.S. experience of single-balloon, double-balloon, and rotational overtube-assisted enteroscopy ERCP in patients with surgically altered pancreaticobiliary anatomy (with video). Gastrointest Endosc. 2013;77:593-600.

57. Shimatani M, Takaoka M, Okazaki K. Tips for double balloon enteroscopy in patients with Roux-en-Y reconstruction and modified Child surgery. J Hepatobiliary Pancreat Sci. 2014;21(4):E22-8.

58. Siddiqui AA, Chaaya A, Shelton C, et al. Utility of the short double-balloon enteroscope to perform pancreaticobiliary interventions in patients with surgically altered anatomy in a US multicenter study. Dig Dis Sci. 2013;58:858-64.

59. Sunada K, Yamamoto H. Double-balloon endoscopy: past, present, and future. J Gastroenterol. 2009;44:1-12.

60. Sunada K, Yano T, Arashiro M, et al. Endoscopic therapy using double balloon endoscopy. Nihon Rinsho. 2008;66:1268-76.

61. Tsutsumi K, Kato H, Tomoda T, et al. Partial stent-in-stent placement of biliary metallic stents using a short double-balloon enteroscopy. World J Gastroenterol. 2012;18:6674-6.
62. Wang WL, Wu ZH, Sun Q, et al. Meta-analysis: the use of carbon dioxide insufflation vs. room air insufflation for gastrointestinal endoscopy. Aliment Pharmacol Ther. 2012;35:1145-54.

63. Yano T, Yamamoto H. Current state of double balloon endoscopy: the latest approach to small intestinal diseases. J Gastroenterol Hepatol. 2009;24:185-92.

64. Aktas H, Mensink PB. Therapeutic balloon-assisted enteroscopy. Dig Dis. 2008;26:309-13.

65. Dellon ES, Kohn GP, Morgan DR, Grimm IS. Endoscopic retrograde cholangiopancreatography with single-balloon enteroscopy is feasible in patients with a prior Roux-en-Y anastomosis. Dig Dis Sci. 2009;54:1798-803.

66. Neumann H, Fry LC, Meyer F, et al. Endoscopic retrograde cholangiopancreatography using the single balloon enteroscope technique in patients with Roux-en-Y anastomosis. Digestion. 2009;80:52-7.

67. Itoi T, Ishii K, Sofuni A, et al. Single balloon enteroscopyassisted ERCP using rendezvous technique for sharp angulation of Roux-en-Y limb in a patient with bile duct stones. Diagn Ther Endosc. 2009;2009:154084.

68. Azeem N, Tabibian JH, Baron TH, et al. Use of a single-balloon enteroscope compared with variable-stiffness colonoscopes for endoscopic retrograde cholangiography in liver transplant patients with Roux-en-Y biliary anastomosis. Gastrointest Endosc. 2013;77:568-77.

69. Itoi T, Ishii K, Sofuni A, et al. Ultrathin endoscope-assisted ERCP for inaccessible peridiverticular papilla by a single-balloon enteroscope in a patient with Roux-en-Y anastomosis. Dig Endosc. 2010;22:334-6.

70. Itoi T, Ishii K, Sofuni A, et al. Single-balloon enteroscopy-assisted ERCP in patients with Billroth II gastrectomy or Roux-en-Y anastomosis (with video). Am J Gastroenterol. 2010;105:93-9.

71. Lennon AM, Kapoor S, Khashab M, et al. Spiral assisted ERCP is equivalent to single balloon assisted ERCP in patients with Roux-en-Y anatomy. Dig Dis Sci. 2012;57:1391-8.

72. Li K, Huang YH, Yao W, et al. Adult colonoscopy or singleballoon enteroscopy-assisted ERCP in long-limb surgical bypass patients. Clin Res Hepatol Gastroenterol. 2014.

73. Moreels TG, Pelckmans PA. Comparison between double-balloon and single-balloon enteroscopy in therapeutic ERC after Roux-en-Y entero-enteric anastomosis. World J Gastrointest Endosc. 2010;2:314-7.

74. Obana T, Fujita N, Ito K, et al. Therapeutic endoscopic retrograde cholangiography using a single-balloon enteroscope in patients with Roux-en-Y anastomosis. Dig Endosc. 2013;25:601-7.

75. Shah RJ, Smolkin M, Yen R, et al. A multicenter, U.S. experience of single-balloon, double-balloon, and rotational overtube-assisted enteroscopy ERCP in patients with surgically altered pancreaticobiliary anatomy (with video). Gastrointest Endosc. 2013;77:593-600.

76. Tomizawa Y, Sullivan CT, Gelrud A. Single balloon enteroscopy (SBE) assisted therapeutic endoscopic retrograde cholangiopancreatography (ERCP) in patients with Roux-en-Y anastomosis. Dig Dis Sci. 2014;59:465-70.

77. Wang AY, Sauer BG, Behm BW, et al. Single-balloon enteroscopy effectively enables diagnostic and therapeutic retrograde cholangiography in patients with surgically altered anatomy. Gastrointest Endosc. 2010;71:641-9.

78. Yamauchi H, Kida M, Okuwaki K, et al. Short-type single balloon enteroscope for endoscopic retrograde cholangiopancreatography with altered gastrointestinal anatomy. World $\mathbf{J}$ Gastroenterol. 2013;19:1728-35.

79. Araki A, Tsuchiya K, Okada E, et al. Single-operator doubleballoon endoscopy (DBE) is as effective as dual-operator DBE. J Gastroenterol Hepatol. 2009;24:770-5. 
80. Hotta K, Katsuki S, Ohata K, et al. A multicenter, prospective trial of total colonoscopy using a short double-balloon endoscope in patients with previous incomplete colonoscopy. Gastrointest Endosc. 2012;75:813-8.

81. Aktas H, Mensink PB. Therapeutic balloon-assisted enteroscopy. Dig Dis. 2008;26:309-13.

82. Albert JG, Nachtigall F, Wiedbrauck F, et al. Minimizing procedural cost in diagnosing small bowel bleeding: comparison of a strategy based on initial capsule endoscopy versus initial double-balloon enteroscopy. Eur J Gastroenterol Hepatol. 2010;22:679-88.

83. Ayala I, Latorre R, Soria F, et al. A case of lymphocytic-plasmacytic jejunitis diagnosed by double-balloon enteroscopy in a dog. J Am Anim Hosp Assoc. 2011;47:262-7.

84. Barreto-Zuñiga R, Tellez-Avila FI, Chavez-Tapia NC, et al. Diagnostic yield, therapeutic impact, and complications of double-balloon enteroscopy in patients with small-bowel pathology. Surg Endosc. 2008;22:1223-6.

85. Becx MC, Al-Toma A. Double-balloon endoscopy: an effective rescue procedure after incomplete conventional colonoscopy. Eur J Gastroenterol Hepatol. 2014.

86. Bellutti M, Fry LC, Schmitt J, et al. Detection of neuroendocrine tumors of the small bowel by double balloon enteroscopy. Dig Dis Sci. 2009;54:1050-8.

87. Beppu K, Osada $\mathrm{T}$, Inoue $\mathrm{K}$, et al. Intestinal involvement in Wegener's granulomatosis diagnosed and followed up by double balloon enteroscopy. Intern Med. 2011;50:219-22.

88. Büschel P, Mönkemüller K, von Falkenhausen U, et al. Emergency double balloon enteroscopy: a feasible and promising diagnostic as well as possible therapeutic option in recurrent midgut bleeding. BMJ Case Rep. 2011;2011.

89. Byeon JS, Jung KW, Song HS, et al. A pilot study about tolerability to double balloon endoscopy: comparison to esophagogastroduodenoscopy and colonoscopy. Dig Dis Sci. 2009;54:2434-40.

90. Chen LH, Cao HJ, Zhang H, et al. Diagnostic values of doubleballoon enteroscopy and abdominal computed tomography in small bowel disease. Zhonghua Yi Xue Za Zhi. 2008;88:3305-8.

91. Chen N, Lamba R, Lee J, Lall C. Mesenteric air embolism following enteroscopic small bowel tattooing procedure. J Clin Imaging Sci. 2012;2:86.

92. Cheon JH, Kim WH. Recent advances of endoscopy in inflammatory bowel diseases. Gut Liver. 2007;1:118-25.

93. Chiu KW, Lu LS, Wu KL, et al. Surveillance culture monitoring of double-balloon enteroscopy reprocessing with high-level disinfection. Eur J Clin Investig. 2012;42:427-31.

94. Das A. Future perspective of double balloon endoscopy: newer indications. Gastrointest Endosc. 2007;66:S51-3.

95. Delvaux M, Gay G. International conference on capsule and double-balloon endoscopy (ICCD). Paris, 27-28 August 2010. Endoscopy. 2011;43:533-9.

96. Giri K, Sudar C, Arya M, Haber G, Chandra P. Diagnosis of marginal cell lymphoma of small intestine by double balloon enteroscopy. South Med J. 2008;101:561-4.

97. Ibuka T, Tsurumi H, Araki H, et al. Clinical significance of jejunoileal involvement of non-Hodgkin's lymphoma detected by double-balloon enteroscopy. Int J Hematol. 2013;97:369-81.

98. Kopacova M, Tacheci I, Rejchrt S, Bures J. Peutz-Jeghers syndrome: diagnostic and therapeutic approach. World J Gastroenterol. 2009;15:5397-408.

99. Kunizaki M, Hidaka S, Isomoto H, et al. Diagnosis of smallbowel metastasis of hepatocellular carcinoma by double-balloon enteroscopy. Int J Surg Case Rep. 2012;3:263-5.

100. Liu K, Kaffes AJ. Review article: the diagnosis and investigation of obscure gastrointestinal bleeding. Aliment Pharmacol Ther. 2011;34:416-23.
101. Maeda M, Kanke K, Sasai T, et al. ${ }^{18}$ F-fluorodeoxyglucose PET/ $\mathrm{CT}$ and small bowel endoscopy in a patient with small bowel leiomyoma. Nihon Shokakibyo Gakkai Zasshi. 2012;109:1561-6.

102. Mellow MH, Kanatzar A. The Oklahoma experience with double balloon enteroscopy: first one hundred procedures. J Okla State Med Assoc. 2009;102:359-61.

103. Mensink PB, Haringsma J, Kucharzik T, et al. Complications of double balloon enteroscopy: a multicenter survey. Endoscopy. 2007;39:613-5.

104. Mensink PB, Kuipers EJ. Double-balloon enteroscopy of the small intestine. Ned Tijdschr Geneeskd. 2007;151:2087-93.

105. Mönkemüller K, Fry LC, Neumann H, et al. Diagnostic and therapeutic utility of double balloon endoscopy: experience with 225 procedures. Acta Gastroenterol Latinoam. 2007;37:216-23.

106. Mönkemüller K, Neumann H, Meyer F, et al. A retrospective analysis of emergency double-balloon enteroscopy for smallbowel bleeding. Endoscopy. 2009;41:715-7.

107. Mönkemüller K, Weigt J, Treiber G, et al. Diagnostic and therapeutic impact of double-balloon enteroscopy. Endoscopy. 2006;38:67-72.

108. Möschler O, May AD, Müller MK, et al. Complications in double-balloon-enteroscopy: results of the German DBE register. Z Gastroenterol. 2008;46:266-70.

109. Nakamura M, Ohmiya N, Hirooka Y, et al. Endoscopic diagnosis of follicular lymphoma with small-bowel involvement using video capsule endoscopy and double-balloon endoscopy: a case series. Endoscopy. 2013;45:67-70.

110. Nakamura T, Terano A. Capsule endoscopy: past, present, and future. J Gastroenterol. 2008;43:93-9.

111. Ogino H, Ochiai T, Nakamura N, et al. Duplication cyst of the small intestine found by double-balloon endoscopy: a case report. World J Gastroenterol. 2008;14:3924-6.

112. Okazaki H, Fujiwara Y, Sugimori S, et al. Prevalence of midgastrointestinal bleeding in patients with acute overt gastrointestinal bleeding: multi-center experience with 1,044 consecutive patients. J Gastroenterol. 2009;44:550-5.

113. Oshitani N, Yukawa T, Yamagami H, et al. Evaluation of deep small bowel involvement by double-balloon enteroscopy in Crohn's disease. Am J Gastroenterol. 2006;101:1484-9.

114. Reuter S, Bettenworth D, Mees ST, et al. A typical presentation of a rare cause of obscure gastrointestinal bleeding. World J Gastrointest Endosc. 2011;3:40-5.

115. Schulz C, Mönkemüller K, Salheiser M, et al. Double-balloon enteroscopy in the diagnosis of suspected isolated Crohn's disease of the small bowel. Dig Endosc. 2014;26:236-42.

116. Sun B, Rajan E, Cheng S, et al. Diagnostic yield and therapeutic impact of double-balloon enteroscopy in a large cohort of patients with obscure gastrointestinal bleeding. Am J Gastroenterol. 2006;101:2011-5.

117. Sunada K, Yamamoto H. Double-balloon endoscopy: past, present, and future. J Gastroenterol. 2009;44:1-12.

118. Sunada K, Yamamoto H. Technology and indications. Gastrointest Endosc Clin N Am. 2009;19:325-33.

119. Sunada K, Yano T, Arashiro M, Miyata T, Yamamoto H. Endoscopic therapy using double balloon endoscopy. Nihon Rinsho. 2008;66:1268-76.

120. Suzuki T, Matsushima M, Okita I, et al. Clinical utility of double-balloon enteroscopy for small intestinal bleeding. Dig Dis Sci. 2007;52:1914-8.

121. Suzuki T, Matsushima M, Tsukune Y, et al. Double-balloon endoscopy versus magnet-imaging enhanced colonoscopy for difficult colonoscopies, a randomized study. Endoscopy. 2012;44:38-42.

122. Takeda T, Shibuya T, Osada T, et al. Metastatic renal cell carcinoma diagnosed by capsule endoscopy and double balloon endoscopy. Med Sci Monit. 2011;17:CS15-7. 
123. Takenaka H, Ohmiya N, Hirooka Y, et al. Endoscopic and imaging findings in protein-losing enteropathy. J Clin Gastroenterol. 2012;46:575-80.

124. Tee HP, Kaffes AJ. Non-small-bowel lesions encountered during double-balloon enteroscopy performed for obscure gastrointestinal bleeding. World J Gastroenterol. 2010;16:1885-9.

125. Terauchi S, Snowberger N, Demarco D. Double-balloon endoscopy and Peutz-Jeghers syndrome: a new look at an old disease. Proceedings (Bayl Univ Med Cent). 2006;19:335-7.

126. Teshima CW, Aktas H, Haringsma J, Kuipers EJ, Mensink PB. Single-balloon-assisted colonoscopy in patients with previously failed colonoscopy. Gastrointest Endosc. 2010;71:1319-23.

127. Thoma MN, Saiyed SM, Charles RJ. Metastatic colorectal cancer to the small bowel-an uncommon cause of obscure GI bleeding: a three-case experience with review of the literature. J Gastrointest Cancer. 2011;42:119-22.

128. van der Veer WM, Hekmat H, Mulder CJ, Jacobs MA. Doubleballoon enteroscopy for the diagnosis and treatment of patients with unexplained gastrointestinal blood loss. Ned Tijdschr Geneeskd. 2007;151:2077-81.

129. Wang WL, Wu ZH, Sun Q, et al. Meta-analysis: the use of carbon dioxide insufflation vs. room air insufflation for gastrointestinal endoscopy. Aliment Pharmacol Ther. 2012;35:1145-54.

130. Yano T, Yamamoto H. Current state of double balloon endoscopy: the latest approach to small intestinal diseases. J Gastroenterol Hepatol. 2009;24:185-92.

131. Zhou N, Chen WX, Chen SH, et al. Inflammatory bowel disease unclassified. J Zhejiang Univ Sci B. 2011;12:280-6.

132. Teshima CW, Aktas H, Haringsma J, et al. Single-balloonassisted colonoscopy in patients with previously failed colonoscopy. Gastrointest Endosc. 2010;71:1319-23.

133. Aktas H, Mensink PB. Therapeutic balloon-assisted enteroscopy. Dig Dis. 2008;26:309-13.
134. Arai Y, Kato T, Arihiro S, et al. Utility of single balloon enteroscopy (SBE) for difficult cases of total colonoscopy. J Interv Gastroenterol. 2012;2:12-4.

135. Coppola F, Gaia S, Cosimato M, Recchia S. Enteroscope without overtube for cecal intubation after an incomplete colonoscopy. Dig Liver Dis. 2011;43:475-7.

136. Curcio G, Sciveres M, Mocciaro F, et al. Out-of-reach obscure bleeding: single-balloon enteroscopy to diagnose and treat varices in hepaticojejunostomy after pediatric liver transplant. Pediatr Transplant. 2012;16:E78-80.

137. Kobayashi K, Mukae M, Ogawa T, et al. Clinical usefulness of single-balloon endoscopy in patients with previously incomplete colonoscopy. World J Gastrointest Endosc. 2013;5:117-21.

138. Li K, Huang YH, Yao W, et al. Adult colonoscopy or singleballoon enteroscopy-assisted ERCP in long-limb surgical bypass patients. Clin Res Hepatol Gastroenterol. 2014.

139. Lin S, Rockey DC. Obscure gastrointestinal bleeding. Gastroenterol Clin North Am. 2005;34:679-98.

140. Rispo A, Imbriaco M, Celentano L, et al. Noninvasive diagnosis of small bowel Crohn's disease: combined use of bowel sonography and Tc-99 m-HMPAO leukocyte scintigraphy. Inflamm Bowel Dis. 2005;11:376-82.

141. Rispo A, Imbriaco M, Celentano L, et al. Small bowel Crohn's disease: comparison of enteroclysis, bowel sonography and Tc99 m-HMPAO leukocyte scintigraphy. Eur Rev Med Pharmacol Sci. 2004;8:219-24.

142. May A, Färber M, Aschmoneit I, et al. Prospective multicenter trial comparing push-and-pull enteroscopy with the single- and double-balloon techniques in patients with small-bowel disorders. Am J Gastroenterol. 2010;105:575-81.

143. Takano N, Yamada A, Watabe H, et al. Single-balloon versus double-balloon endoscopy for achieving total enteroscopy: a randomized, controlled trial. Gastrointest Endosc. 2011;73:734-9. 